\title{
Relation between arterial pressure, dietary sodium intake, and renin system in essential hypertension
}

\author{
P S PARFREY, N D MARKANDU, J E ROULSTON, B E JONES, J C JONES, G A MACGREGOR
}

\begin{abstract}
Forty-one patients with mild essential hypertension, 36 patients with severe hypertension, and 28 normotensive subjects were studied on a high sodium intake of $350 \mathrm{mmol} / \mathrm{day}$ for five days and low sodium intake of $10 \mathrm{mmol} /$ day for five days. The fall in mean arterial pressure on changing from the high-sodium to the low-sodium diet was $0.7 \pm 1.7 \mathrm{~mm} \mathrm{Hg}$ in normotensive subjects, $8 \pm 1.4 \mathrm{~mm} \mathrm{Hg}$ in patients with mild hypertension, and $14.5 \pm 1.4 \mathrm{~mm} \mathrm{Hg}$ in patients with severe hypertension. The fall in blood pressure was not correlated with age. Highly significant correlations were obtained for all subjects between the ratio of the fall in mean arterial pressure to the fall in urinary sodium excretion on changing from a high- to a low-sodium diet and (a) the level of supine blood pressure on normal diet, (b) the rise in plasma renin activity, and (c) the rise in plasma aldosterone.

In patients with essential hypertension the blood pressure is sensitive to alterations in sodium intake. This may be partly due to some change either produced by or associated directly with the hypertension. A decreased responsiveness of the renin-angiotensinaldosterone system shown in the patients with essential hypertension could partly account for the results.
\end{abstract}

\section{Introduction}

The role of dietary sodium intake in essential hypertension is disputed. ${ }^{12}$ Recent evidence shows that there is only a small change in blood pressure with alteration of dietary sodium intake in normotensive subjects. ${ }^{3-5}$ In essential hypertension, however, a modest reduction in dietary sodium intake may cause a significant fall in blood pressure, ${ }^{6}{ }^{7}$ although in some hypertensive subjects the blood pressure does not fall. ${ }^{8}$ Few comparative studies have been conducted on the short- and long-term effects that altering dietary sodium intake has on the blood pressure in both normotensive subjects and hypertensive subjects. Borst and Borst-de Geus ${ }^{9}$ were the first to suggest that "Deficient sodium excretion must be an essential factor in all types of persistent hypertension." If this is so, a reduction in dietary sodium intake should cause a greater fall in blood pressure in patients with hypertension than in normotensive subjects, unless irreversible structural changes have occurred in the patients with hypertension. Consequently we studied the fall in blood pressure that occurred on changing from a high to a low sodium intake in a group of patients with essential hypertension and compared their response to the response of a

\footnotetext{
Departments of Medicine and Nuclear Medicine, Charing Cross Hospital Medical School, London W6 8RF

P S PARFREY, MD, MRCP, lecturer in medicine

N D MARKANDU, SRN, research assistant

J E ROULSTON, MA, MRSC, senior biochemist (present appointment: lecturer in biochemistry, Royal Infirmary, Edinburgh)

B E JONES, BSC, MSC, principal physicist

J C JONES, BSC, MSC, biochemist

G A MACGREGOR, MA, MRCP, senior lecturer in medicine and honorary consultant physician
}

group of normotensive subjects. Changes in urinary sodium excretion, weight, plasma volume, and the renin-angiotensinaldosterone system were also measured.

\section{Patients}

Seventy-seven patients with essential hypertension, referred by local general practitioners, were studied. Patients were excluded if there was evidence of renal failure, (plasma creatinine concentration $>120 \mu \mathrm{mol} / \mathrm{l}$ ), ischaemic heart disease, or cerebrovascular disease and if they were taking oral contraceptives or any other drug. Either the subjects studied had not received previous treatment or their treatment had stopped three months before the study. All subjects were followed for three months in the blood-pressure unit before an imposed change in sodium intake. At the end of the three months patients were admitted to the study if their supine diastolic blood pressure was greater than $90 \mathrm{~mm} \mathrm{Hg}$ and less than $130 \mathrm{~mm} \mathrm{Hg}$. During the analysis of the results two groups of hypertensive subjects were arbitrarily defined: those whose supine diastolic blood pressure on the last day of normal dietary sodium intake was 90 to $109 \mathrm{~mm} \mathrm{Hg}$ (mild essential hypertension) and those whose diastolic blood pressure was 110 to $130 \mathrm{~mm} \mathrm{Hg}$ (severe hypertension). In the mildly hypertensive group there were 20 men and 21 women, 11 of the group were black. In the severe group there were 18 men and 18 women, 15 were black. The severe group were significantly older (mean age $=$ $50 \pm 1.4$ years) than the mildly hypertensive group (mean age $=$ $44+1.9$ years). The results of these groups were compared with the results of a group of normotensive subjects, most of whom were hospital-based personnel. The normal subjects (17 men and 11 women, including six blacks) had a mean supine diastolic blood pressure on normal sodium intake of less than $85 \mathrm{~mm} \mathrm{Hg}$. Mean age of the normotensive group was $33 \pm \mathbf{2 \cdot 6}$ years. Informed consent was obtained from each subject.

\section{Methods}

Subjects were studied on a high sodium intake of $350 \mathrm{mmol} /$ day for five days and a low sodium intake of $10 \mathrm{mmol} /$ day for five days. High sodium intake was achieved by supplementing the normal diet with 20 slow sodium tablets $(200 \mathrm{mmol}$ sodium/day). The potassium intake was not altered for either diet. A low-sodium diet was provided by the metabolic ward kitchen. During the study period 24-hour urinary collections were made during the last two days of both dietary periods. The subjects were not admitted to hospital and were allowed to go about their normal activities but were discouraged from vigorous exercise. All blood pressures were measured by nurses using semi-automatic observer bias-free ultrasound sphygmomanometers with recorders (Arteriosonde 1217). ${ }^{10}$ The mean value of five readings taken in the supine position at 1-2 minute intervals was recorded. Blood pressure was measured between 10 am and 12 noon in the same room by the same nurse on the final day of the normal diet and on the fifth day of high- and low-sodium diets. Pulse rate was measured on a Cambridge 3048 pulse monitor with electrocardiogram display and recording. Body weight was recorded at each visit.

Biochemistry-Urinary and plasma electrolytes and creatinine concentrations were measured by autoanalyser. After blood pressure measurement, blood was taken and tested for plasma electrolytes, urea and creatinine concentrations, renin activity, ${ }^{11}$ and aldosterone concentration $^{12}$ on the last day of the normal, high- and low-sodium diets, subjects having been seated upright for 10 minutes. Plasma volume was measured only in the hypertensive patients using ${ }^{131}$ Ialbumin.

Statistics-Mean arterial pressure (MAP) was calculated as diastolic pressure $+(1 / 3 \times$ pulse pressure $)$. As an index of the sensitivity of the arterial pressure to a change in sodium intake, the ratio of the 
fall in mean arterial pressure to the fall in 24-hour urinary sodium excretion ( $\triangle M A P: \Delta U N a V$ ) on changing from the high- to the low-sodium diet was calculated. Student's two-tailed $t$ test and nonparametric analyses were carried out using the statistical package for the social sciences at the University of London computer.

\section{Results}

Table I shows the results obtained on the final day of the normal sodium intake (before alteration of sodium intake) for the normotensive and hypertensive subjects. There was no significant difference in plasma creatinine concentration, 24-hour urinary sodium and potassium excretion, or pulse rate between the three groups. The hypertensive subjects were, however, older and heavier and had a lower plasma renin activity than normotensive subjects.

Normotensive subjects-The fall in sodium intake was accompanied by small changes in blood pressure and large changes in plasma renin activity and aldosterone concentration (table II). The fall of mean arterial pressure on changing from the high- to the lowsodium diet was minimal $(0 \cdot 7+\mathrm{SEM} 1 \cdot 7 \mathrm{~mm} \mathrm{Hg})$. The ratio of the fall in mean arterial pressure to the fall in urinary sodium excretion on changing from the high- to the low-sodium diet was $0.004=0.006$. This ratio was not correlated with age $(r=0 \cdot 17, n=28)$. In a subgroup of normal subjects older than 30 years $(n-12$, mean age $=45.2$ years), the change in mean arterial pressure was $1.7 \pm 1.05 \mathrm{~mm} \mathrm{Hg}$, and the ratio was $0.005: 0.003$, neither value being significantly different from that in the normotensive group as a whole.

Mild hypertension-In contrast to the normotensive subjects there was a significant fall in mean blood pressure in subjects with mild hypertension when the sodium intake was reduced $(8 \cdot 0 \therefore 1.4 \mathrm{~mm} \mathrm{Hg}$, $p=0.002$ ). The percentage fall in blood pressure was also significantly greater than in the normotensive group. The ratio ( $\triangle \mathrm{MAP}: \Delta \mathrm{UNaV}$ ) was $0.03: 0.006$, which was significantly greater than the ratio in normal subjects. The increase in plasma renin activity and aldo-

TABLE I-Mean SE blood pressure, pulse rate, urinary sodium and potassium excretion, weight, and plasma hormones of hypertensive and normotensive subjects on the last day of normal diet

\begin{tabular}{|c|c|c|c|}
\hline & $\begin{array}{c}\text { Normotensive } \\
\text { subjects }\end{array}$ & $\begin{array}{l}\text { Patients with } \\
\text { mild essential } \\
\text { hypertension }\end{array}$ & $\begin{array}{l}\text { Patients with } \\
\text { severe } \\
\text { hypertension }\end{array}$ \\
\hline $\begin{array}{l}\text { Systolic blood pressure } \\
(\mathrm{mm} \mathrm{Hg})\end{array}$ & $119: 2$ & $161: 2$ & $187 \div 3$ \\
\hline $\begin{array}{l}\text { Diastolic blood pressure } \\
(\mathrm{mm} \mathrm{Hg})\end{array}$ & $75: 2$ & $102 \div 1$ & $118+2$ \\
\hline Pulse rate $\mathrm{min}$ & $75 \div 2$ & $77: 2$ & $76: 1$ \\
\hline Weight (kg) & $71 \div 2$ & $74: 2$ & $75: 2$ \\
\hline $\begin{array}{l}\text { Urinary sodium } \\
(\mathrm{mmol} / 24)\end{array}$ & $168 \div 10$ & $145: 8$ & $153: 8$ \\
\hline $\begin{array}{l}\text { Urinary potassium } \\
(\mathrm{mmol} / 24)\end{array}$ & $70 \cdot 5 \pm 4 \cdot 3$ & $62 \cdot 0: 2 \cdot 6$ & $58 \cdot 6: 3 \cdot 2$ \\
\hline $\begin{array}{l}\text { Plasma renin activity } \\
(\mathrm{ng} / \mathrm{ml} / \mathrm{h}) \text { (sitting) }\end{array}$ & $2 \cdot 14 \div 32$ & $0.93 \div 0.11$ & $0.81: 0.12$ \\
\hline $\begin{array}{l}\text { Plasma aldosterone } \\
(\mathrm{pmol} 1) \text { (sitting) }\end{array}$ & $488: 51$ & $417: 51$ & $476+41$ \\
\hline Plasma volume (1) & & $2 \cdot 78: 0.09$ & $2 \cdot 75 \pm \cdot 08$ \\
\hline
\end{tabular}

sterone concentration was significantly less $(\mathbf{p}=0.002)$ than that in the normotensive subjects (table II).

Severe hypertension - In patients with severe hypertension the fall in .arterial pressure on reducing sodium intake was significantly greater than in the group with mild hypertension when calculated as absolute fall, percentage fall, or fall in blood pressure divided by fall in urinary sodium excretion. The change in mean arterial pressure from the high to the low sodium diet was $14.7 \pm 1.4 \mathrm{~mm} \mathrm{Hg}$, and $\triangle M A P: \triangle \mathrm{UNaV}$ was $0 \cdot 106 \pm 0 \cdot 023$. The rise in plasma renin activity and aldosterone concentration on changing from high- to lowsodium diets was significantly smaller than in the other two groups. Urinary sodium excretion on the high-sodium diet was lower in this group than in the other two groups, but it was not significantly different on the low-sodium diet. The absolute levels of plasma renin activity and aldosterone concentration on low-sodium diet were significantly lower in the group with severe hypertension than in the group with mild hypertension.

All subjects-Using the ratio $\triangle \mathrm{MAP}: \triangle \mathrm{UNaV}$ from a high to a low sodium intake as an index of the sensitivity of the arterial pressure to a reduction in sodium intake we correlated this ratio, using the non-parametric Spearman correlation coefficient, with a number of other variables. The figure shows that there was a highly significant correlation between the ratio and systolic blood pressure measured supine on the last day of the normal diet (an index of the severity of hypertension $)(\mathrm{r}=0.47, \mathrm{n}=105, \mathrm{p}<0.001)$. There was no significant

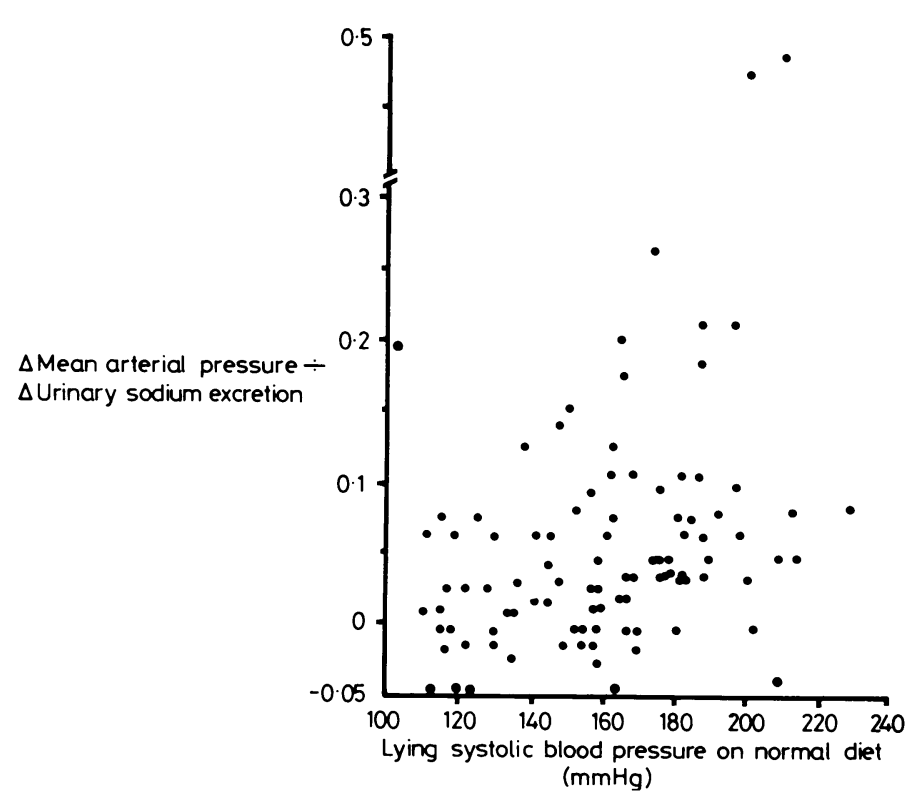

The relation between the ratio of the fall in mean arterial pressure from high to low sodium intake to the fall in 24 -hour urinary sodium excretion and the supine systolic blood pressure on normal sodium intake in all subjects.

TABLE II-Mean $\rfloor S E$ of supine blood pressure, pulse rate, 24-hour urinary sodium and potassium excretion, weight, plasma renin activity, aldosterone concentration and volume during high sodium and low sodium intake in patients with mild and severe hypertension and in normotensive subjects. $\Delta$ refers to the difference between each variable comparing levels on high-and low-sodium diets

\begin{tabular}{|c|c|c|c|c|c|c|c|c|c|}
\hline & \multicolumn{3}{|c|}{ Normotensive subjects } & \multicolumn{3}{|c|}{ Patients with mild hypertension } & \multicolumn{3}{|c|}{ Patients with severe hypertension } \\
\hline & High sodium & Low sodium & $\Delta$ & High sodium & Low sodium & $\Delta$ & High sodium & Low sodium & $\Delta$ \\
\hline $\begin{array}{l}\text { Systolic blood pressure } \\
\text { (mm Hg) }\end{array}$ & $119 \cdot 3: 2 \cdot 8$ & $116 \cdot 4 ! 2 \cdot 8$ & $3 \cdot 1: 2 \cdot 0$ & $160 \cdot 2 \pm 2 \cdot 4$ & $146 \cdot 4 \div 2 \cdot 5$ & $13 \cdot 8 \pm 1 \cdot 9$ & $189 \cdot 2 \pm 3 \cdot 1$ & $165 \cdot 8 \pm 3 \cdot 0$ & $23 \cdot 5 \pm 2 \cdot 6$ \\
\hline $\begin{array}{l}\text { Diastolic blood pressure } \\
\text { (mm Hg) }\end{array}$ & $75 \cdot 4: 1 \cdot 7$ & $75 \cdot 9=2 \cdot 1$ & $-0.5 \div 2.0$ & $101 \cdot 2 \pm 1 \cdot 2$ & $96 \cdot 2 \div 1 \cdot 4$ & $5 \cdot 1+1 \cdot 4$ & $119 \cdot 6 \pm 1 \cdot 7$ & $109 \cdot 3 \pm 1 \cdot 8$ & $10 \cdot 3 \pm 1 \cdot 5$ \\
\hline Pulse rate $\min$ & $74 \cdot 6: 2 \cdot 8$ & $76 \cdot 4: 2 \cdot 6$ & $1 \cdot 8: 2 \cdot 5$ & $78 \cdot 0 \pm 1 \cdot 5$ & $77 \cdot 7+1 \cdot 5$ & $0.3 \pm 1.5$ & $78 \cdot 6 \pm 1 \cdot 8$ & $79 \cdot 9 \pm 2 \cdot 0$ & $-1 \cdot 3 \pm 1 \cdot 8$ \\
\hline $\begin{array}{l}\text { 24-hour urinary sodium } \\
(\mathrm{mmol})\end{array}$ & $310: 14$ & $15 \div 2$ & $294 \div 15$ & $293 \pm 15$ & $19 \pm 2$ & $274 \pm 15$ & $244 \pm 20$ & $22 \pm 3$ & $222 \pm 19$ \\
\hline $\begin{array}{l}\text { 24-hour urinary potassium } \\
\text { (mmol) }\end{array}$ & $71 \cdot 0: 4 \cdot 9$ & $61 \cdot 7: 3 \cdot 9$ & $8 \cdot 2: 5 \cdot 4$ & $62 \cdot 7 \pm 2 \cdot 7$ & $48 \cdot 9+2 \cdot 6$ & $14 \cdot 1 \pm 2 \cdot 9$ & $56 \cdot 0 \pm 3 \cdot 1$ & $44 \cdot 5 \pm 1 \cdot 7$ & $11 \cdot 0 \pm 3 \cdot 0$ \\
\hline Weight (kg) & $70 \cdot 9: 1.9$ & $69 \cdot 0 \div 1 \cdot 8$ & $2 \cdot 38 \pm 0 \cdot 18$ & $74 \cdot 1 \pm 2 \cdot 4$ & $71 \cdot 9 \pm 2 \cdot 3$ & $2 \cdot 14 \pm 0 \cdot 15$ & $75 \cdot 3 \pm 1 \cdot 9$ & $73 \cdot 4 \pm 1 \cdot 9$ & $1 \cdot 83 \pm \cdot 13$ \\
\hline Plasma volume (1) & & & & $2.89 \pm 0.09$ & $2 \cdot 6 \pm 0.08$ & $0.28 \pm 0.04$ & $2 \cdot 78 \pm 0 \cdot 07$ & $2 \cdot 62 \pm 0.07$ & $0.19 \pm 0.06$ \\
\hline $\begin{array}{l}\text { Plasma renin activity } \\
(\mathrm{ng} / \mathrm{ml} / \mathrm{h})\end{array}$ & $0.65: 0.11$ & $5 \cdot 71 \div 0 \cdot 61$ & $-4.79 \div 0.54$ & $0 \cdot 49 \cdot 0 \cdot 07$ & $3.09 \pm 0.42$ & $-2 \cdot 6 \pm 0 \cdot 42$ & $0.5 \pm 0.09$ & $2.0 \pm 0.32$ & $-1.5 \pm 0.3$ \\
\hline $\begin{array}{l}\text { Plasma aldosterone } \\
\triangle M A P: \triangle \text { Urinary sodium }\end{array}$ & $257: 21$ & $1480 \pm 146$ & $\begin{array}{rl}-1223 & +136 \\
0.004 & 0.006\end{array}$ & $271 \pm 44$ & $901 \div 110$ & $\begin{aligned}-630 & \pm 115 \\
0.03 & \pm 0.006\end{aligned}$ & $356 \pm 32$ & $728 \pm 85$ & $\begin{array}{l}-356 \pm 91 \\
0 \cdot 106 \pm 0 \cdot 023\end{array}$ \\
\hline
\end{tabular}


correlation between the ratio $\triangle \mathrm{MAP}: \triangle \mathrm{UNaV}$ and age in either the normal or the hypertensive groups. This ratio was significantly correlated with the rise in plasma renin activity on changing from high- to low-sodium diets $(r=-0.49, \mathrm{n}=98, \mathrm{p}<0.001)$ and the rise in plasma aldosterone concentration $(r=-0.47, n=68, p<$ $0.001)$ but not with the fall in weight $(r=-0.09, n=100, p=N S)$ or the fall in plasma volume $(r=-0 \cdot 13, n=69, p=N S)$. Although the black hypertensive subjects had a larger fall in blood pressure on reduction of sodium intake than white hypertensive subjects the significant relation between level of blood pressure and $\triangle M A P: \triangle U N a V$ was present in white subjects alone. The blood pressure response to reduction of sodium intake was similar in men and women.

Potassium intake-Daily urinary potassium excretion on normal diet was significantly higher in normotensive subjects compared with hypertensive subjects (table I). A significant inverse correlation was obtained for all subjects between level of supine systolic blood pressure on normal diet and 24-hour urinary potassium excretion $(\mathrm{r}=-0.25, \mathrm{n}=101, \mathrm{p}<0.01)$. The change in potassium excretion from high to low sodium diet was not significantly correlated with the $\Delta \mathrm{MAP}: \Delta \mathrm{UNaV}(\mathrm{r}=-0 \cdot 13, \mathrm{p}=\mathrm{NS})$.

\section{Discussion}

Our results show that on reducing sodium intake blood pressure fell significantly in patients with essential hypertension but not in normotensive subjects. The small change in blood pressure we have observed in normal subjects is similar to those recently reported. ${ }^{3-5}$ There have been few published reports, however, concerning the relation between arterial pressure and urinary sodium excretion in both hypertensive and normotensive subjects. Fujita et $a l^{8}$ studied "salt-sensitive" and "non-salt-sensitive" hypertensive patients using an arbitrary cut-off point to define their non-salt-sensitive patients, rather than using normotensive controls. Recently a preliminary report ${ }^{13}$ has shown that a higher proportion of "borderline" hypertensive patients than of normal controls had a blood pressure rise in response to an acute increase in sodium intake. Only 19 patients were studied, however.

The relation between blood pressure and sodium intake in hypertensive subjects may not be linear. Increasing the sodium intake from the normal-sodium diet to a high-sodium diet caused only a small rise in blood pressure, whereas reducing the sodium intake from a high- to a low-sodium diet produced a fall in blood pressure similar to that which occurred with a reduction in the sodium intake from a normal- to a low-sodium diet. This project, however, was designed specifically to observe the changes that occurred from a high- to a low-sodium diet. Therefore we analysed our results comparing levels on a high- and a low-sodium intake. When the results obtained on a normal- and a low-sodium diet are compared the differences between hypertensive and normotensive subjects are even greater than those discussed here.

In the patients with severe hypertension the urinary sodium excretion on the high-sodium diet was significantly less than that in the patients with mild hypertension. This may have been due to incomplete compliance, though all three groups were treated alike. It may have been due to a decreased appetite for sodium in patients with severe hypertension, as has been suggested by Schecter et al. ${ }^{14}$ Another possibility is that sodium is not so well absorbed from the gut in patients who have low plasma renin activities and perhaps associated high concentrations of a circulating sodium transport inhibitor. The changes in weight and plasma volume do not support the suggestion that sodium was retained, but this could be definitely excluded only by performing accurate sodium balance studies.

It has been suggested that deficient sodium excretion may play a part in the pathogenesis of hypertension. ${ }^{9}$ If this were true, alteration of sodium intake would cause a significant change in blood pressure. We have shown that reducing sodium intake from a large amount to a small amount produces a significantly greater fall (both in absolute and percentage terms) in arterial pressure in patients with severe hypertension than in patients whose hypertension was not so severe. Furthermore, the fall in arterial pressure on reducing the intake of sodium is significantly correlated with severity of hypertension. This suggests that the height of the blood pressure might determine the extent of the fall in pressure which occurs when the sodium intake is reduced. For instance, the high blood pressure may damage or accentuate the kidney's inability to excrete sodium. This renal defect may be intrinsic to the kidney or extrinsic (entailing hormones which increase or decrease urinary sodium excretion). Hypertension changes kidney function in ways that favour maintenance of hypertension, as shown by the observations that renal vascular resistance increases with time in hypertensive patients ${ }^{15}$ and that relative renal retention of sodium and potassium occurs in hypertensive patients after exercise stress, a finding not observed in normotensive subjects. ${ }^{1617}$ Partial or totally irreversible changes in renal function induced by hypertension could perpetuate the hypertension.

The changes of blood pressure reported here may be explicable by abnormalities in other pressure control mechanisms. The correlation analysis suggests that some of the variability in the pressure changes that occurred on alteration of sodium intake can be explained by the severity of the patient's blood pressure and by suppression of the renin-angiotensin-aldosterone system. Patients with low-renin hypertension have significantly higher blood pressure than patients with normal or high renin, ${ }^{19}$ as observed in this project. Blood pressure is sensitive to volume changes in patients with low-renin hypertension. ${ }^{18}$ Therefore, part of the explanation for our results may be that the decreased responsiveness of the renin system to the decrease in sodium intake in the hypertensive subjects prevented the normal compensatory increase in angiotensin II and aldosterone. Recently Dahl's hypothesis that a saluretic substance may be responsible for a sustained rise in arterial pressure has been extended to essential hypertension. ${ }^{20}$ High concentrations of circulating sodium transport inhibitor, in the presence of low levels of plasma renin activity, have already been observed in essential hypertension. ${ }^{21} \mathrm{~A}$ change in sodium intake and consequent change in fluid volume, may decrease the concentration of circulating sodium transport inhibitor and consequently blood pressure may fall. As yet we have no evidence to confirm or refute this suggestion. Patients with the greatest pressure sensitivity to a change in sodium intake may have the least changes in plasma catecholamine concentrations ${ }^{8}$ or the greatest change in vascular reactivity to catecholamines. Again we have no evidence in favour or against this proposition. It is interesting that Fujita $e t a^{8}$ have suggested that the greater increase in blood pressure in their salt-sensitive patients with sodium loading may be attributed to greater sodium retention, leading in turn to an increase in cardiac output. Our results do not support this suggestion because the changes in plasma volume which we observed were not correlated with the change in blood pressure.

Normally therefore blood pressure changes little after a decrease in sodium intake, but in essential hypertension a significant depressor response may follow. This pressure sensitivity to a change in sodium intake is partly caused by some change either produced by or associated with the hypertension itself. A decreased responsiveness of the reninangiotensin-aldosterone system may partly account for the results observed in the subjects with essential hypertension.

These studies were supported by the Medical Research Council, The Wellcome Trust and the National Kidney Research Fund. We thank Dr A P Roberts and Professor H E de Wardener for their advice during preparation of the manuscript.

\section{References}

${ }^{1}$ Simpson FO. Salt and hypertension: a sceptical review of the evidence. Clin Sci 1979;57, suppl 5:463-80s.

2 Swales JD. Dietary salt and hypertension. Lancet 1980;i:1177-80. 
${ }^{3}$ Luft FC, Rankin LI, Bloch R, et al. Cardiovascular and humoral responses to extremes of sodium intake in normal black and white man. Circulation $1979 ; 60: 697-706$.

${ }^{4}$ Romoff MS, Kensch G, Campese VM, et al. Effect of sodium intake on plasma catecholamines in normal subjects. F Clin Endocrinol Metab $1979 ; 48: 26-31$.

${ }^{5}$ Burstyn P, Hornall D, Walchorn C. Sodium and potassium intake and blood pressure. $\mathrm{Br}$ Med f 1980 ;281 :537-9.

${ }^{6}$ Parijs J, Joosens JV, Van der Linden L, Verstrchan G, Amery AKPC. Moderate sodium restriction and diuretics in the treatment of hypertension. Am Heart $\mathcal{F} 1973 ; 85: 22-34$.

7 Morgan T, Gillies A, Morgan G, Adam W, Wilson M, Carney S. Hypertension treated by salt restriction. Lancet $1978 ; \mathrm{i}: 227-30$.

${ }^{8}$ Fujita T, Henry WL, Bartter FC, Lake RC, Delea CS. Factors influencing blood pressure in salt-sensitive patients with hypertension. $\mathrm{Am} \mathcal{F} \mathrm{Med}$ 1980;69:334-44.

9 Borst JG, Borst-de Geus A. Hypertension explained by Starling's theory of circulatory homeostasis. Lancet $1963 ; \mathrm{i}: 677-82$.

10 George CF, Lewis PJ, Petrie A. Clinical experience with use of ultrasound sphygmonanometer. Br Heart $\mathcal{f}$ 1975;37:804-7.

11 Roulston JE, MacGregor GA. Measurement of plasma renin activity by radioimmunoassay after prolonged cold storage. Clin Chim Acta 1978; $88: 45-8$.

12 James VHT, Wilson GA. Determination of aldosterone in biological fluids. In: Reid E, ed. Assay of drugs and other trace compounds in biological fluids. (Methodological developments in biochemistry. Vol 5.) Amsterdam: Elsevier/North Holland, 1976:149-58.

${ }^{13}$ Sullivan JM, Ratts TE, Taylor CJ, et al. Haemodynamic effects of dietary sodium in man. A preliminary report. Hypertension 1980;2:506-14.

14 Schechter PJ, Horwitz D, Henkin RI. Sodium chloride preference in essential hypertension. f $A M A 1973 ; 225: 1311-5$.

15 Schalekamp MADH, Schalekamp-Kuyken MPA, Birkenhager WH. Abnormal renal haemodynamics and renin suppression in hypertensive patients. Clin Sci 1970;38:101-10.

${ }_{16}$ Parfrey PS, Wright P, Ledingham PS. Prolonged isometric exercise Part 1: Effect on circulation and on renal excretion of sodium and potassium in mild essential hypertension. Hypertension $1981 ; 3: 182-7$.

17 Parfrey PS, Wright P, Ledingham PS. Prolonged isometric exercise. Part 2: Effect on circulation and on renal excretion of sodium and potassium in young males genetically predisposed to hypertension. Hypertension $1981 ; 3: 188-91$.

${ }^{18}$ Laragh JH, Baer L, Brunner HR, Buhler FR, Sealey BS, DarracottVaughan E. Renin, angiotensin and aldosterone system in pathogenesis and management of hypertensive vascular disease. $A m \mathcal{F}$ Med 1972 ; 52:633-52.

19 Campese VM, Myers MR, De Quattro V. Neurogenic factors in low renin essential hypertension. Am $\mathcal{F}$ Med 1980;69:83-91.

20 de Wardener HE, MacGregor GA. Dahl's hypothesis that a saluretic substance may be responsible for a sustained rise in arterial pressure: its possible role in essential hypertension. Kidney Int 1980;18:1-9.

${ }^{21}$ MacGregor GA, Fenton S, Alaghband-Zadeh J, Markandu ND, Roulston $\mathrm{JE}$, de Wardener $\mathrm{HE}$. An increase in a circulating inhibitor of $\mathrm{Na}^{+}-$ $\mathrm{K}^{+}$-ATPase-the link between salt intake and the development of essential hypertension. Clin Sci Mol Med (in press).

(Accepted 20 May 1981)

\title{
Poor sensitivity of multiple-gated blood-pool imaging in diagnosing left ventricular aneurysms
}

\author{
A P ALLEN, I PEART, D N TAYLOR, B R CONDON, B C OGILVIE, J W FRANK, H SUTTON, \\ D M ACKERY
}

\begin{abstract}
A study was carried out to determine the accuracy of multiple-gated blood-pool imaging in diagnosing left ventricular aneurysm. Fifteen patients with an aneurysm and 17 with left ventricular hypokinesia were studied by contrast ventriculography and multiple-gated blood-pool imaging. The results of blood-pool imaging were examined blind by five independent observers, the results of contrast ventriculography being used as the standard. The mean sensitivity of the procedure was $56 \%$, the specificity $61 \%$, and diagnostic accuracy $59 \%$.

These results indicate that contrast ventriculography remains the best method for diagnosing left ventricular aneurysms. Moreover, ventriculography provides additional information-for example, on wall thickness-not provided by multiple-gated blood-pool imaging.
\end{abstract}

\section{Introduction}

Ischaemic heart disease may be associated with global left ventricular hypokinesia (left ventricular "bag") or localised impairment of motion of the ventricular wall (an aneurysm). Differentiation between these two conditions is important as a patient with an aneurysm may benefit from cardiac surgery. Such differentiation cannot be done clinically, ${ }^{12}$ and at present contract ventriculography performed at cardiac catheterisation is the only method that will reliably distinguish the two conditions. This procedure has a small but important morbidity and mortality, so in recent years non-invasive radionuclide techniques have been examined as alternatives. It is important to determine whether radionuclide dynamic imaging is as successful as conventional contrast ventriculography in distinguishing between left ventricular aneurysms and left ventricular bags. This study was designed to evaluate the use of equilibrium radionuclide bloodpool imaging in making this distinction.

\section{Patients, methods, and results}

Thirty-two patients underwent contrast ventriculography in the right anterior oblique position and multiple-gated blood-pool imaging in both the right and left anterior oblique positions. Only patients with either an aneurysm (15) or a left ventricular bag (17) were included. In each case the result of multiple-gated blood-pool imaging was examined by five independent observers (with no knowledge of the result of contrast ventriculography) and classified as "aneurysm" or "not aneurysm." An aneurysm was defined as a region of akinesia or dyskinesia with good function in the remainder of the left ventricle. Diagnostic accuracy was defined as the percentage of patients correctly identified using contrast ventriculography as the standard. The table shows the results of the study for each observer.

A P ALLEN, MB, BS, senior house officer in nuclear medicine and cardiology I PEART, MB, MRCP, registrar in cardiology

D N TAYLOR, BTECH, PHD, senior
B R CONDON, BSC, MSC, physicist

B C OGILVIE, MRCP, FRCR, consultant radiologist

J W FRANK, MSC, FRCR, consultant radiologist

H SUTTON, MB, MS, senior registrar in nuclear medicine

D M ACKERY, MB, MSC, consultant in nuclear medicine 